\title{
Characterization of Colorless Coated Cubic Zirconia (Diamantine)
}

James E. Shigley, Al Gilbertson, and Sally Eaton-Magaña

Over the past several years, diamond simulants have entered the market that consisted of colorless cubic zirconia reportedly coated with a thin layer (e.g., represented to be $30-50 \mathrm{~nm}$ ) of nanocrystalline diamond particles embedded in a matrix. One manufacturer, Serenity Technologies (Temecula, California), has marketed this material as Diamantine. SIMS chemical analysis of samples obtained from Serenity in October 2009 indicated a very thin $(\sim 5 \mathrm{~nm})$ film of carbon (along with Al and Ti) on the CZ surface. Durability tests performed in conjunction with SEM imaging demonstrated that the thin coating does not completely withstand typical gemstone cleaning and handling procedures. The only standard gemological technique that could establish the presence of a coating was EDXRF spectroscopy, which detected $\mathrm{Ti}$ from the adhesion layer deposited on the $\mathrm{CZ}$ during the initial part of the coating process.

S ophisticated techniques used in the semiconductor and optical coating industries are now being applied to the treatment of gemstones. In the past few years, the jewelry industry has witnessed the introduction of several faceted gem materials (diamond, topaz, quartz, cubic zirconia, and others) reportedly coated with thin colored or colorless surface layer(s) of substances such as aluminum oxide, diamond-like carbon (DLC), and nanocrystalline synthetic diamond to change their color or allegedly improve their appearance and/or durability (see, e.g., Henn, 2003; Shen et al., 2007; Ogden, 2008; Schmetzer, 2008; Bennet and Kearnes, 2009). These new coating treatments present several important challenges for the jewelry trade, including their proper description, identification, determination of any visual or physical effects resulting from the coating, and disclosure (see box A).

For the past several years, Serenity Technologies of Temecula, California, has produced and marketed a simulant consisting of faceted cubic zirconia (CZ) coated with what is described as a thin, transparent, colorless layer containing submicroscopic particles of nanocrystalline synthetic diamond embedded in a matrix material (see figure 1 and www.serenitytechnology.com). This product is currently sold under the brand name Diamantine and is distributed only through licensed dealers. The

See end of article for About the Authors and Acknowledgments. Gems \& Gemology, Vol. 48, No. 1, pp. 18-30,

http://dx.doi.org/10.5741/GEMS.48.1.18.

(C) 2012 Gemological Institute of America

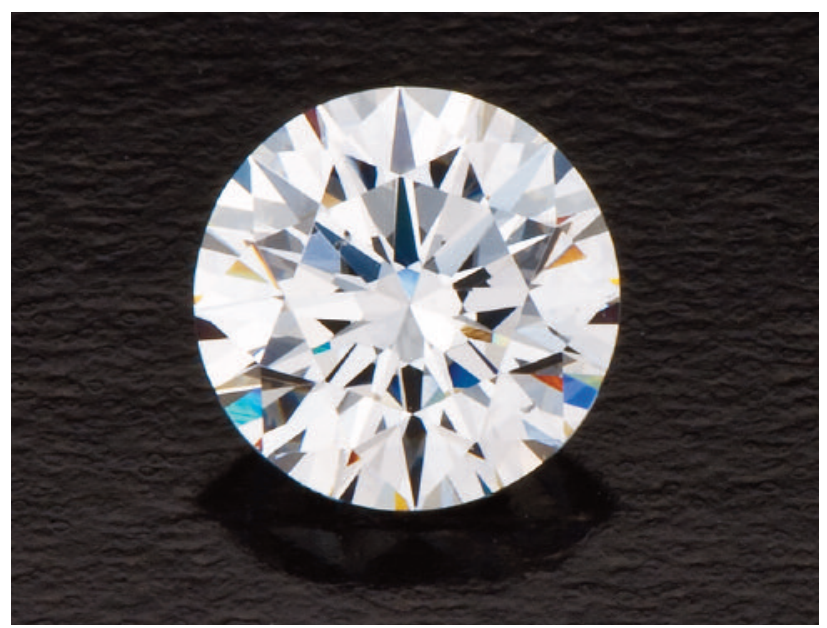

Figure 1. This cubic zirconia $(2.00 \mathrm{ct}$ ) has been coated by Serenity Technologies with a proprietary colorless thin layer that is said to consist of "nanocrystalline diamond particles" embedded in a matrix. Photo by Robert Weldon.

Diamantine production process has a capacity of 2,000 carats in each cycle, for a total of 20,000 carats per day (S. Neogi, pers. comm., 2009). Colorless and variously colored thin-film layers can be deposited on CZ by this process. With modifications to the surface-cleaning procedure, similar layers can also be deposited on other gem materials, including emerald, opal, and tanzanite. Colored gemstones coated with diamond-like carbon have been available in the trade for years (Koivula and Kammerling, 1991). 


\section{Box A: QUESTIONS SURROUNDING THE IDENTIFICATION AND DisClOSURE Of Thin-Film Coatings ON Gemstones}

The availability of gemstones and pearls with thin colored or colorless coatings, containing not only synthetic diamond but possibly other materials, poses real challenges for gem identification and treatment disclosure. The jewelry trade needs to consider such questions as:

1. What requirement does a gemological laboratory, gemologist, appraiser, or jeweler have to disclose the presence of a coating that may not be detectable or permanent?

2. What is the requirement to disclose a colorless coating when it does not appear to change the gem material's properties, appearance, or durability?

3. Does a layer on the surface of a polished gem material have a thickness threshold, above which it would be considered a coating (requiring legal disclosure) and below which it would be considered a surface contamination (not requiring disclosure)?
4. What proof is necessary from a producer before making claims that a coating of a given thickness offers protection or improves the underlying gem material's optical characteristics?

5. What responsibility do sellers of gem materials with colorless coatings have to substantiate claims regarding the benefits provided by the coating?

6. What guidelines regarding coating durability and coating permanence should be established for a treated gem material?

7. While advanced gemological testing techniques currently in use are designed to analyze the bulk chemical and spectral properties of a gem material, what techniques will be required now and in the future to detect and identify coatings on the polished surfaces of gem materials?
The present study was undertaken to determine the nature of the colorless coating on Diamantine. Earlier, Eaton-Magaña and Chadwick (2009) examined 14 samples of colorless EternityCZ, marketed by Serenity as "nanocrystalline synthetic diamond coated" cubic zirconia. Since the coating technology may change over time, it is unclear if the material they examined is the same as the product described here. In both instances, the coated samples displayed the gemological properties of cubic zirconia.

\section{WHAT IS DIAMANTINE?}

Serenity's website indicates that Diamantine is produced by a proprietary process - which consists of a thorough cleaning of the CZ facet surfaces, followed by a plasma-enhanced ion deposition-to create a coating on the $\mathrm{CZ}$ consisting of a dispersion of tiny carbon-containing particles embedded in a matrix. The website indicates this process "involves the development of a coating of nanocrystalline diamond particles of size below $60 \mathrm{~nm}$ uniformly on all cut surfaces of the gem material utilizing Serenity's proprietary nanodiamond technology... The average size of these particle clusters varies between 5-30 nm." An illustration on Serenity's website shows the Diamantine coating consisting of three portions, as seen in cross-section: an "adhesion layer" deposited directly on the surface of the $\mathrm{CZ}$ to help the carbon-containing particles adhere to the substrate, a thicker intermediate layer containing "nanocrystalline diamond" particles embedded randomly in a more abundant matrix material, and a "protective outer layer."

A study of the structure of the coating layer was commissioned by Serenity in February 2009 and was performed by Evans Analytical Group (EAG) in Santa Clara, California. The full results compiled by EAG may be found on Serenity's website. High-resolution transmission electron microscopy (HRTEM) produced high-magnification $(>100,000 \times)$ images showing the combined thickness of the coating was on the order of $50 \mathrm{~nm}$. In these HRTEM images, the coating did not appear to be evenly distributed, which suggests that it may be thinner or even absent from small regions of the gem's surface. Additional images at 138,000 × magnification obtained using scanning electron microscopy (SEM) clearly showed the presence of nanocrystalline particles in the size range of $5-20 \mathrm{~nm}$. Chemical analysis of selected areas of the coating on two Diamantine samples by energy-dispersive X-ray spectroscopy (EDS) detected the following elements in varying concentrations: $\mathrm{Al}, \mathrm{Ti}, \mathrm{Si}, \mathrm{O}, \mathrm{Zr}$, and $\mathrm{C}$. Some spots showed high $\mathrm{Zr}$ and low $\mathrm{C}$ concentrations, which suggests that the coating was either absent or present only as an extremely thin layer on the substrate CZ.

The Serenity-EAG 2009 study also included an electron diffraction pattern image that was obtained 
by passing an electron beam through a very thin vertical cross-section of the coating and the CZ substrate. Within the coating layer were small regions of crystalline material (with a regular arrangement of distinct layers of atoms) in an otherwise structurally amorphous matrix (with randomly arranged atoms) that appeared to constitute most of the coating. The (hkl) spacings between atomic layers within the small crystalline regions corresponded to the lattice spacings in diamond (111), as well as those in metallic $\mathrm{Al}$ (002) and $\mathrm{Ti}$ (102), as stated on Serenity's website. The lattice spacings in another coating corresponded only to diamond, with no $\mathrm{Al}$ and $\mathrm{Ti}$, which Serenity representatives interpreted as indirect evidence of "nanocrystalline diamond" particles in the coating.

We did not have the opportunity to examine the coated CZ samples studied by EAG. As with the results by Eaton-Magaña and Chadwick (2009) on Serenitycoated CZ, we can only assume that those samples were similar to the ones examined here.

\section{MATERIALS AND METHODS}

Materials. The Diamantine product uses CZ starting material that is cut and polished to higher standards than most cubic zirconia in the market. We also obtained very well-cut CZ samples for Serenity to coat for us. These samples did not exhibit the typical poor symmetry and facet polish seen in commercial CZ, but instead were cut to precise angles so their face-up appearance pattern mimicked that of the best cut-grade ranges for round brilliant-cut diamonds.

Sixty-five cubic zirconia samples were initially used in the study; all were standard round brilliants weighing 1.41-2.08 ct. Of these samples, 39 were coated by Serenity in the fall of 2009 and early 2010 to create their colorless Diamantine product, while the remaining 26 were left uncoated for comparison. Each of these 65 samples was first laser-inscribed on the girdle surface with a project identification number. Each was examined with $10 \times$ magnification by experienced GIA laboratory staff who plotted any minor surface imperfections using standard diamond clarity grading procedures.

In addition to the coated faceted samples, one of two flat polished CZ plates measuring $7.5 \mathrm{~mm}$ in diameter was "thickly" coated $(100 \mathrm{~nm})$ by Serenity for this study in October 2009.

As mentioned above, in the Diamantine material that is sold commercially, a thin layer is applied as a protective surface on top of the layer containing the carbon nanoparticles. To assist GIA in analyzing the underlying carbon-containing layer, in April 2010

\section{In Brief}

- Diamantine (like uncoated CZ) is easily distinguished from diamond on the basis of thermal conductivity.

- When imaged by SEM, the coating contains nanocrystalline particles that appear consistent with diamond. However, testing by methods available to us could not confirm their identity.

- These nanocrystalline particles did not completely remain on the $\mathrm{CZ}$ after simple durability tests (such as cleaning with a polishing cloth, with or without alcohol).

- Serenity is reportedly planning to release a new version of Diamantine, along with a testing device that can detect the coating.

Serenity provided five additional coated faceted CZ samples $(1.69-2.01 \mathrm{ct})$ that did not include the adhesion and protective layers.

Six additional faceted samples $(1.74-2.03 \mathrm{ct})$ of Diamantine were purchased through a third party in July 2011.

\section{Gemological Examination and Advanced Data Col-} lection at GIA. Samples of the coated CZ were subjected to standard gemological testing methods to detect any evidence of the coating, its effects, and differences between the coated and uncoated material. For this examination we used a Nikon Eclipse LV100 polarizing microscope with Nomarski differential interference contrast illumination and 1,000× magnification capability.

Representative samples of the coated CZ were also tested with more advanced spectroscopy instrumentation (although Serenity officials maintain that such techniques cannot effectively characterize thin-film coatings). Spectroscopic analyses were performed on both the coated and uncoated polished plates and on 10 coated and several uncoated CZ samples. Infrared absorption spectroscopy was done on carefully cleaned samples in the mid-infrared $\left(6000-400 \mathrm{~cm}^{-1}, 1 \mathrm{~cm}^{-1}\right.$ resolution) and reflective near-infrared (up to 11000 $\mathrm{cm}^{-1}, 4 \mathrm{~cm}^{-1}$ resolution) ranges at room temperature with a Thermo Scientific Nicolet 6700 Fourier-transform infrared (FTIR) spectrometer. A total of 512 scans per spectrum were collected to improve the signal-tonoise ratio. Ultraviolet-visible-near infrared (UV-VisNIR, 250-1000 $\mathrm{nm}$ ) absorption spectra were measured with a PerkinElmer Lambda 950 spectrometer using a $1.0 \mathrm{~nm}$ bandpass. Photoluminescence (PL) and Raman 
spectra were obtained with a Renishaw InVia Raman confocal microspectrometer. Four lasers with five excitation wavelengths were employed to activate optical defects in the coating: an Ar-ion laser at 488 and $514.5 \mathrm{~nm}$, an He-Ne laser at $633 \mathrm{~nm}$, a diode laser at $830 \mathrm{~nm}$, and an He-Cd metal-vapor laser at $325 \mathrm{~nm}$. Raman spectra (typically $2500-500 \mathrm{~cm}^{-1}$, and 1600 $1200 \mathrm{~cm}^{-1}$ for high-accumulation runs) were collected using all five excitation wavelengths. To observe the characteristic diamond Raman peak at $1332 \mathrm{~cm}^{-1}$ we also tried several experimental variations, including the use of liquid-nitrogen temperatures to cool the samples, high magnification during spectra collection, both standard and confocal operating modes, up to 60 accumulations to improve the signal-to-noise ratio, and applying a thin gold layer to the coated surface to facilitate a modified technique known as surface-enhanced Raman spectroscopy (SERS; see Huang et al., 2000; Prawer and Nemanich, 2004).

Qualitative energy-dispersive X-ray fluorescence (EDXRF) data were collected using a Thermo ARL Quant'X EDXRF analyzer to see if $\mathrm{Al}$ and Ti could be detected in the coating on five samples. These were selected from the initial study group of 39 samples; on each one, the table surface was analyzed. Two data acquisition conditions were used to optimize the detection of these elements: (1) for $\mathrm{Al}-4 \mathrm{kV}$ voltage, $1.62 \mathrm{~mA}$ current, no filter, and 100 second count time, under vacuum; (2) for Ti-12 kV voltage, $1.98 \mathrm{~mA}$ current, $\mathrm{Al}$ filter, and 100 second count time, under vacuum. Note that laser ablation-inductively coupled plasma-mass spectrometry (LA-ICP-MS) analysis was not attempted because the coating layer is too thin to be sampled sufficiently by the ablation procedure for analysis.

Coating Characterization at Commercial Analytical Facilities. A second EAG study was commissioned by GIA in October 2009 to investigate the chemical composition of the coating layer. Analyses were carried out by dynamic secondary ion mass spectrometry (SIMS) using a Physical Electronics 6650 quadrupole-based system (figure 2). Because of the high cost of SIMS, only two samples were analyzed: a commercial Diamantine (sample CZ105) and a coated specimen that did not include the adhesion and protective layers; both of these were coated and obtained directly from Serenity.

With the SIMS technique, the sample is bombarded under vacuum conditions with a finely focused, $\sim 50$ mm diameter beam of cesium ions $(1 \mathrm{kV}, 135 \mathrm{nA})$, which results in the ejection and ionization of atoms from the sample. These secondary ions are accelerated into a

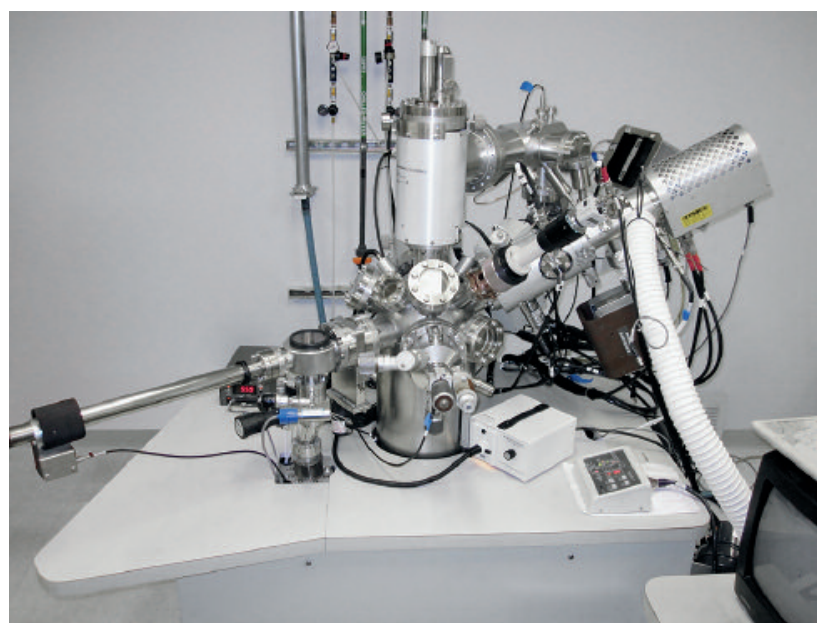

Figure 2. The uncoated and coated CZ samples were analyzed by dynamic secondary ion mass spectrometry (SIMS) at Evans Analytical Group in Santa Clara, California. Photo by Tim Thomas.

double-focusing mass spectrometer, where they are separated according to their energy and mass/charge ratio and detected. Continued exposure of the sample to the beam of cesium ions gradually erodes the target area $(\sim 600 \times 600 \mu \mathrm{m})$ layer-by-layer to form a flatbottomed crater. Over time, data can be obtained at progressively greater depths below the surface to produce a depth profile of the changing chemical composition through the coating down into the substrate CZ. The actual depths of the pits created by SIMS analysis of the Serenity samples were subsequently measured. The elemental concentrations and sputter rates were determined using a calibrated diamond-like carbon test sample. From the pit depth, beam parameters, and milling time, EAG determined the depth of each element in the coating. Several positions on the table facet of each sample were analyzed to ensure the data were representative.

The elements analyzed by SIMS included $\mathrm{H}, \mathrm{C}, \mathrm{N}$, $\mathrm{O}, \mathrm{Al}, \mathrm{Ti}$, and $\mathrm{Zr}$. The results were quantified using the Rayleigh backscattering method on two reference samples, each consisting of a thin layer (30.5 and 150 $\mathrm{nm}$ ) of diamond-like carbon (DLC). This quantification provided a means to convert the signal intensity of ions removed from the sample to element concentration values. The detection limit was $1 \times 10^{19}$ atoms $/ \mathrm{cm}^{3}$ for $\mathrm{H}$, and $1 \times 10^{18}$ atoms $/ \mathrm{cm}^{3}$ for $\mathrm{C}, \mathrm{N}$, and $\mathrm{O}$. The rate of removal (or sputtering) of atoms from the surface by the cesium-ion beam can also provide information on coating composition /since the rate varies with the type of material), and this was also quantified on the 
DLC reference samples. Also analyzed by this method were an amorphous carbon reference standard and a silicon sample coated with microcrystalline synthetic diamond.

Additionally, scanning electron microscopy (SEM) and energy-dispersive X-ray spectroscopy (EDS) was performed on two occasions to examine several coated and uncoated samples at the California Institute of Technology (Caltech) in Pasadena. The instrument consisted of a high-resolution analytical scanning electron microscope (LEO 1550 VP FESEM) equipped with an Oxford INCA Energy 300 EDS system, operated with an accelerating voltage of $10 \mathrm{kV}$ and electron beam current of $10 \mathrm{nA}$. On the first occasion (December 2010), three faceted Diamantines (two obtained in 2009 and one in 2010), the "thickly" coated CZ plate, and one uncoated faceted CZ were imaged by SEM, and then the EDS spectra were collected. Due to the amount of charging on these nonconductive samples, we deposited $10 \mathrm{~nm}$ of conductive carbon using a turbo-carbon evaporator and reimaged the samples at higher magnification (up to 150,000×). On the second occasion (July 2011), we examined five Diamantine samples that had just been purchased through a third party (with a specific request from us to not handle them in any way). We deposited $10 \mathrm{~nm}$ of conductive carbon on the samples and imaged them with SEM.

After SEM analysis, these later five samples were then subjected to durability testing to see how well the coating adhered to the $\mathrm{CZ}$ substrate. (Note that the conductive carbon coating that we applied to these samples would not affect the adhesion of Serenity's coating.) Five tests, each one carried out on a different Diamantine sample, consisted of:

A. Cleaning for 30 seconds with a gem cloth

B. Cleaning for 30 seconds with a gem cloth and alcohol

C. Application of adhesive tape across the table facet

D. Rubbing the table facet for 30 seconds against a slurry of aluminum oxide powder and water on an aluminum oxide-impregnated polishing lap (followed by cleaning with a gem cloth and alcohol)

E. Rubbing the table facet for 30 seconds against 60,000 diamond grit in oil on a polishing lap (followed by cleaning with a gem cloth and alcohol)

We then recoated the five samples with $10 \mathrm{~nm}$ of conductive carbon and reimaged them with the SEM. The durability tests and SEM imaging were completed within four hours after the Diamantine package was initially opened.

Additional Testing. Our initial visual observation and jewelry manufacturing testing experiments are briefly described in box B. The results of these investigations became questionable after our second SEM examination revealed that the coating could be partially removed from Diamantine by simple cleaning procedures. We therefore became concerned that the coatings on the earlier samples used in this testing

\section{Box B: Initial Visual Observation and Jewelry Manufacturing Testing}

Visual Observation Testing. We conducted two rounds of visual observation tests to compare the face-up appearance of the Diamantine product with that of colorless round-brilliant $\mathrm{CZs}$ and diamonds based on GIA's cut-grade parameters (Moses et al., 2004). Our goal was to see if the coating improved the appearance of these CZ samples, producing a stronger resemblance to diamond.

In general, our observers could not distinguish between the face-up appearance of diamond, coated CZ, and uncoated CZ.
Testing of Jewelry Manufacturing Procedures. On its website, Serenity warns customers not to have a Diamantine sample polished, recut, or subjected to heat from a jeweler's torch. We conducted two tests to check the durability of the Diamantine product using typical manufacturing and repair procedures. These consisted of (1) casting a $\mathrm{CZ}$ in place in a ring and (2) finishing a gold ring set with $\mathrm{CZ}$ by filing and finishing the four metal prongs.

We found no difference in the behavior of the coated and uncoated CZ samples in the two repair procedures. 


\begin{tabular}{|c|c|c|c|c|}
\hline & Graphite & Diamond-like carbon & Nanocrystalline diamond & Single-crystal diamond \\
\hline Description & $\begin{array}{l}\text { Crystalline carbon } \\
\text { (graphite) with a } \\
\text { hexagonal structure and } \\
\mathrm{sp}^{2} \text { bonding (and weak } \\
\text { bonding between the } \\
\text { hexagonal layers) }\end{array}$ & $\begin{array}{l}\text { Amorphous carbon with } \\
\text { significant } \mathrm{sp}^{2} \text { bonding in } \\
\mathrm{an} \mathrm{sp}^{3} \text { network, but } \\
\text { without long-range } \\
\text { crystallinity }\end{array}$ & $\begin{array}{l}\text { Uniform distribution of } \\
\text { diamond crystallites (3- } \\
15 \mathrm{~nm} \text { ) with } \mathrm{sp}^{2} \text { carbon } \\
\text { bonding along grain } \\
\text { boundaries }\end{array}$ & $\begin{array}{l}\text { Cubic crystalline carbon } \\
\text { (diamond) with pure } \mathrm{sp}^{3} \\
\text { bonding }\end{array}$ \\
\hline $\begin{array}{l}\text { Approximate amount of } \\
\mathrm{sp}^{3} \text { (i.e., diamond) } \\
\text { bonding }\end{array}$ & $0 \%$ & $33 \%^{a}, 40 \%{ }^{b}$ & $90 \%{ }^{a, c}$ & $100 \%$ \\
\hline Density $\left(\mathrm{g} / \mathrm{cm}^{3}\right)$ & $2.02-2.23$ & $2.9^{d}$ & $3.5^{b}$ & 3.53 \\
\hline Refractive index & $1.8^{\mathrm{e}}$ & $1.75^{\mathrm{f}} ; 1.85-1.95^{\mathrm{a}}$ & $2.0-2.1^{\mathrm{a}} ; 2.34^{\mathrm{g}}$ & 2.418 \\
\hline Vickers hardness (GPa) & $0.14^{h}$ & $5-49^{b} ; 6.5-37^{f}$ & $40-75^{b}$ & $55-113^{b}$ \\
\hline
\end{tabular}

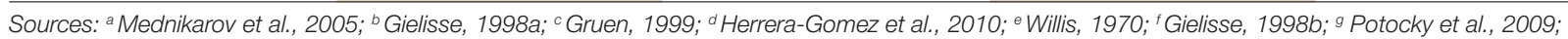

h Patterson et al., 2000.

had been accidentally removed by such cleaning, so the results will not be described here and further study will be needed to address these subjects.

\section{RESULTS}

Gemological Examination. We suspect that during the coating deposition process, one or more carboncontaining materials-including diamond, diamondlike carbon, and carbon (graphite) — could be produced, depending on the deposition conditions. Table 1 provides a comparison of these carbon materials' physical properties.

We found no differences in gemological properties between Diamantine and standard CZ samples. The coating could not be seen in reflected light with a standard gemological microscope, or in polarized transmitted light at $1,000 \times$ magnification. Diamantine was not misidentified as diamond using, for example, a standard thermal conductivity probe.

With the exception of Raman spectroscopy, standard analytical methods and instruments used in major gemological laboratories are unlikely to detect a very thin, colorless, carbon-containing coating on a polished $\mathrm{CZ}$ or other gem material-or, if such a coating is detected, to confirm that the carbon is in the crystalline form of diamond. Raman spectroscopy is the most established method for determining the type of carbon present in a material. The diamond Raman peak (produced by $\mathrm{sp}^{3}$ bonding of carbon atoms) is located at $1332 \mathrm{~cm}^{-1}$, while the graphite-related Raman feature (where the carbon has $\mathrm{sp}^{2}$ bonding) is a broad band centered at $\sim 1550 \mathrm{~cm}^{-1}$ (see Zaitsev, 2001, pp. 69-70, 111-112). Our Raman spectroscopy investigation was unable to detect the $1332 \mathrm{~cm}^{-1}$ or the $\sim 1550 \mathrm{~cm}^{-1}$ peak (figure 3, top), even with a $325 \mathrm{~nm}$ UV laser at liquidnitrogen temperatures on the $\mathrm{CZ}$ plate represented as having a "thick" coating (figure 3, bottom).

We also were unable to establish the presence of the coating using the other spectroscopic techniques available in GIA's laboratory. The results from reflective NIR and UV-Vis-NIR spectra were inconclusive; midFTIR and PL spectroscopy showed only features consistent with the underlying CZ.

EDXRF chemical analysis detected a weak X-ray fluorescence peak characteristic of $\mathrm{Ti}$ in the coating of the tested Diamantine samples. This feature was not detected in the uncoated CZ, thus providing evidence for identifying the presence of one component of the Diamantine coating (figure 4).

SEM Characterization. Two sets of samples were analyzed by SEM to look for visual evidence of the nanocrystalline particles. These tests were an attempt to reproduce Serenity's SEM images at the same or higher magnification. 


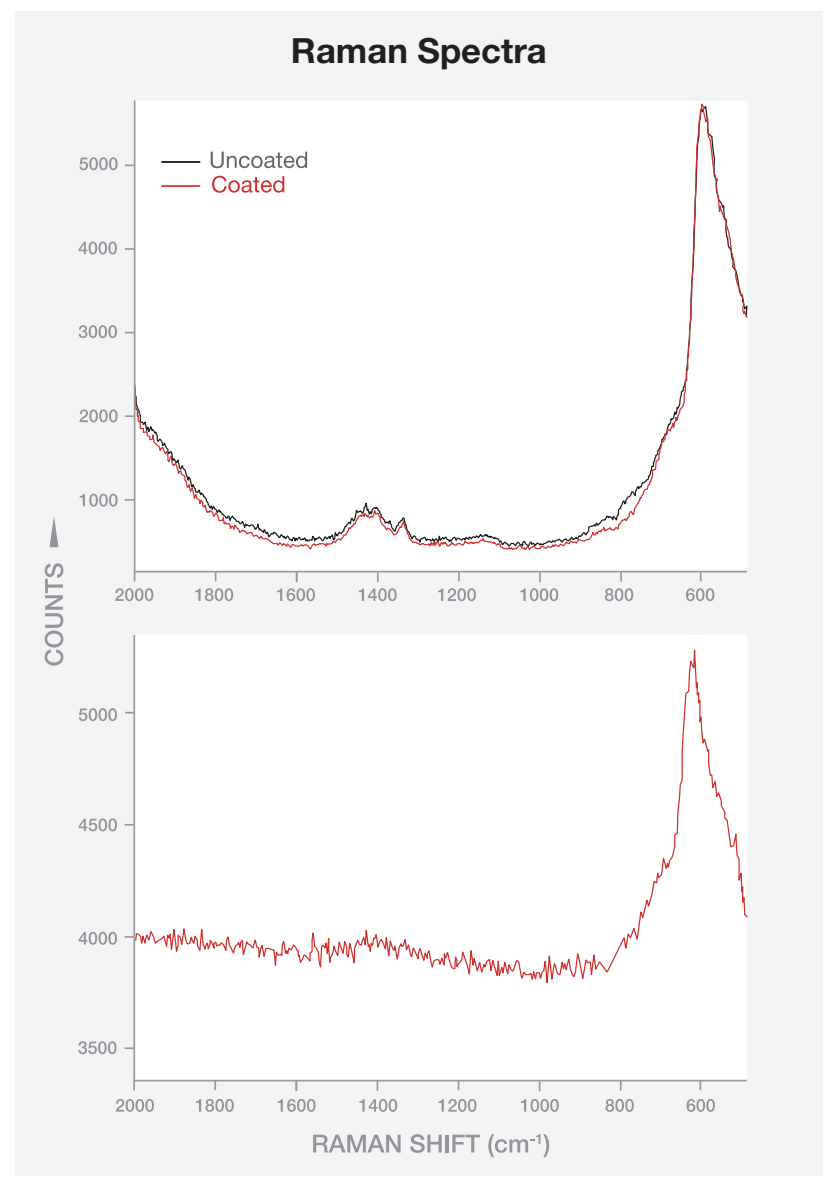

Figure 3. Raman spectra were collected with a $325 \mathrm{~nm}$ laser from a CZ plate before and after a "thick" coating was applied by Serenity Technologies (top). The spectrum for the coated sample overlays that of the uncoated sample, and showed no significant differences in the regions associated with carbon-neither the 1332 $\mathrm{cm}^{-1}$ peak characteristic of diamond nor the $1550 \mathrm{~cm}^{-1}$ peak associated with graphitic carbon. As shown on the bottom, Raman spectra of the coated sample at liquid-nitrogen temperature collected using a $325 \mathrm{~nm}$ laser at 50× magnification and 60 accumulations could not detect the $1332 \mathrm{~cm}^{-1}$ peak in the coating.

The first study was comprised of samples used in other tests that had been in GIA's possession for 7-18 months. During this time, these samples had been subjected to standard procedures of cleaning with isopropyl alcohol and handling with tweezers on numerous occasions. The SEMimages of these "coated" samples generally showed no indication of a coating. Even at very high magnification $(150,000 \times)$, we were unable to observe any nanocrystalline particles. The notable exception was the "thickly" coated plate/figure 5). We observed some small remnants of what appeared to be nanoparticles (figure 5B and 5C), though these
EDXRF Spectra

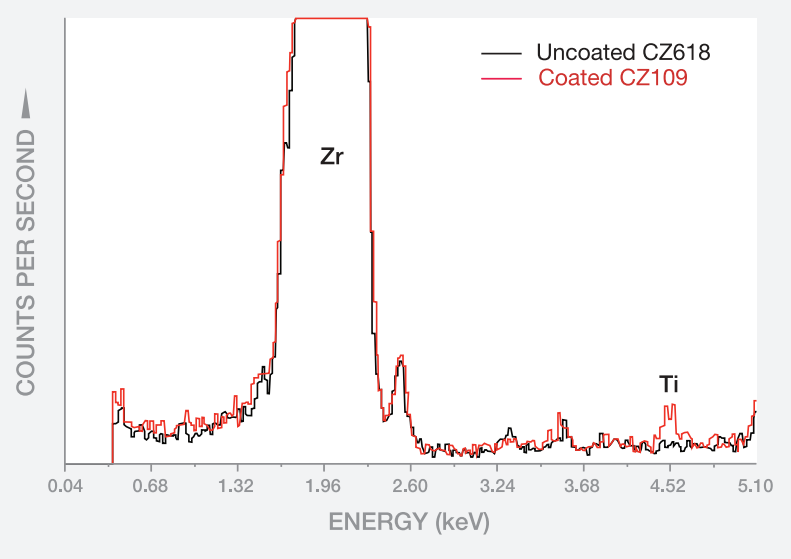

Figure 4. This EDXRF spectrum of a Diamantine sample shows a weak emission peak due to Ti, which is absent from the spectrum of the uncoated $C Z$. The dominant feature in both spectra is the large peak due to $Z$ r.

images were not entirely consistent with the manufacturer's SEM image of the same disk just after coating (figure 5A). The vast majority of the images obtained from surveying the surface of the coated samples were, in contrast, more consistent with the uncoated sample (compare figures 5D and 5E). Very little carbon was detected, generally, and the carbon signature increased with the deposition of the $10 \mathrm{~nm}$ conductive carbon coating.

Unable to observe the coating on these samples, we decided to procure some new, untouched samples and study the conditions that might remove the Diamantine coating. The second SEM study was conducted in July 2011 using samples acquired through the trade, and the packaging was not opened until minutes before the samples were placed in the SEM. In all five samples, we consistently observed crystallites with a grain size of about 50-100 nm (left images in figures 6A-E). However, significant changes were seen in most of the images collected after durability testing. The Serenity coating was somewhat able to withstand the first test (rubbing with a gem cloth), but the other four tests removed the larger crystallites from the CZs (right images in figures 6A-E). Some smaller, low-relief grains underneath the larger crystallites still remained, but most of the "nanocrystalline" component (presumably synthetic diamond) was gone.

These SEM images and EDS spectra clearly indicated that the coating is not durable enough to withstand normal use. The majority of the coating was gone after 


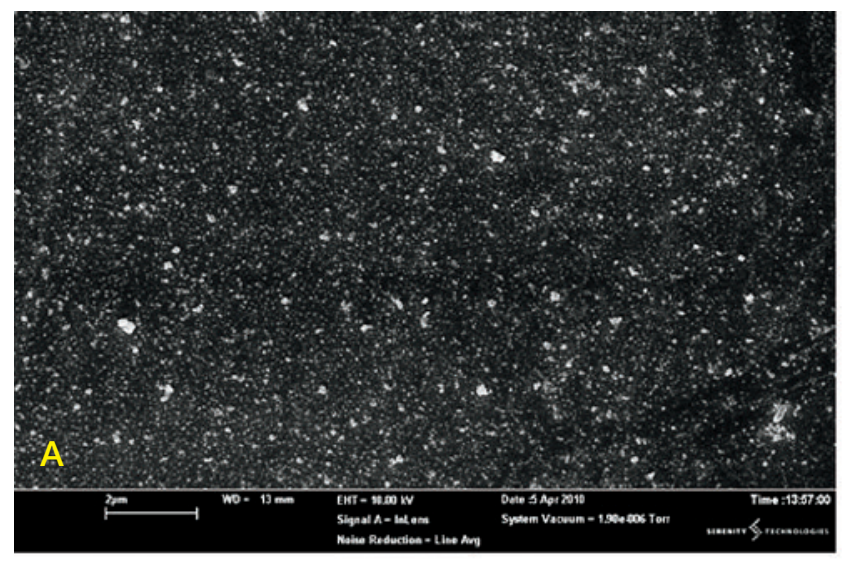

Figure 5. SEM imaging by Serenity of the "thickly" coated CZ plate in April 2010 shows nanocrystallites (A). In December 2010, GIA reimaged this same sample and found only a small region of the surface that showed remnants suggestive of a coating (B). Magnifying this area $150,000 \times$ reveals an appearance consistent with nanodiamond particles (C). Most of the samples analyzed by SEM showed no evidence of a coating, including the pavilion surface of sample CZ507 at 150,000× (D). Instead, the surface appears similar to that of uncoated sample CZ505 at the same magnification (E).
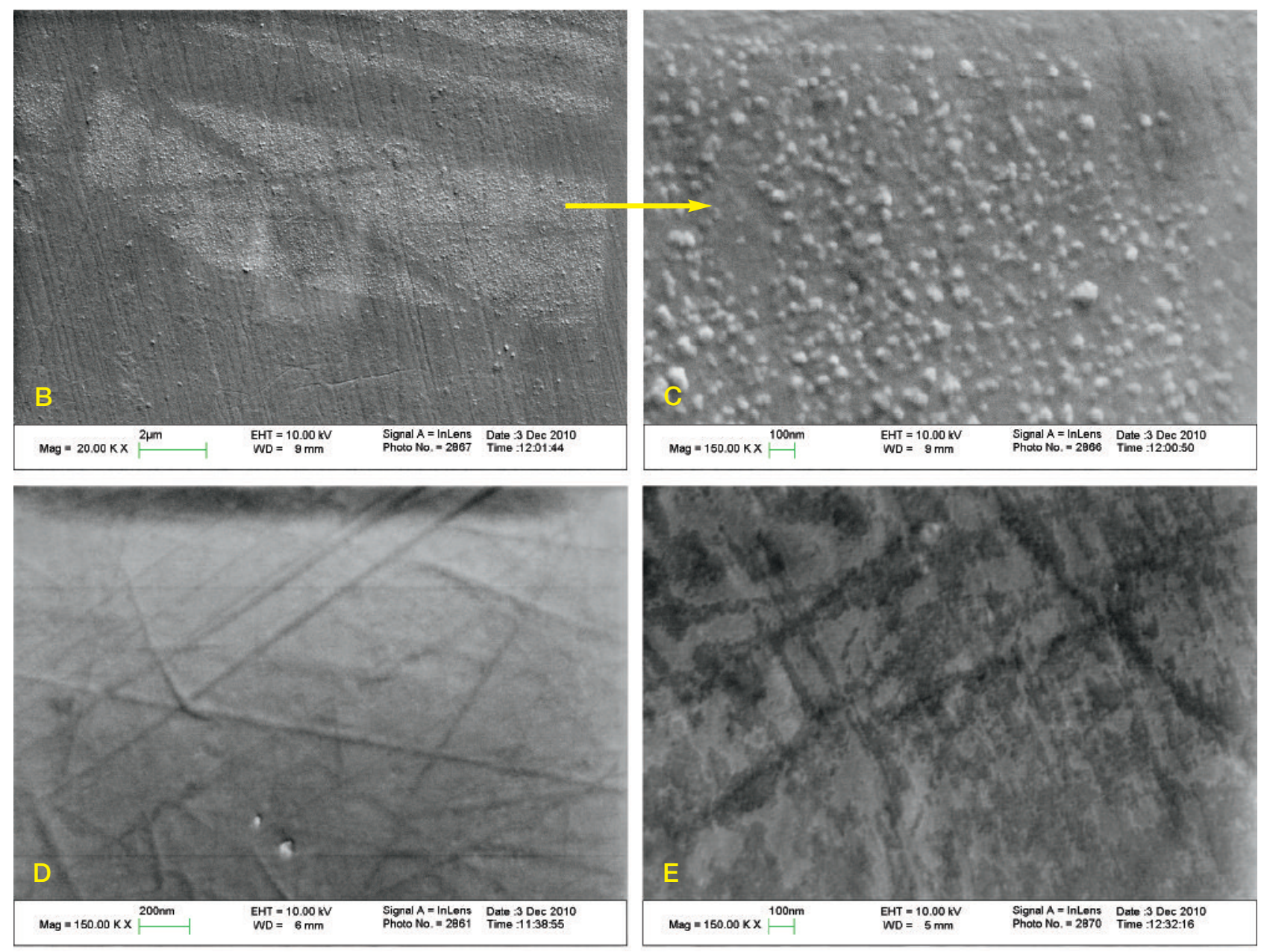

30 seconds of deliberate cleaning or other abrasion /with the exception of simply rubbing the sample with a gem cloth). When subjected to longer periods of standard use-handling with tweezers, gemological testing, and cleaning with a gem cloth or isopropyl alcohol-the coating seems to disappear entirely; even the small low-

relief grains observed in the "after" images of the durability study are no longer present. These results call into question the stability of this coating in real-world applications. Because the coating is colorless, it would be difficult (if not impossible) for a gemologist or consumer to verify the continued existence of the 
Figure 6. This series of beforeand-after SEM images (magnified 100,000x-200,000x)

showcases the effects of various durability tests on a set of never-handled Diamantine samples acquired in July 2011. All of the "before" images show crystallites, most of which were removed by the durability tests. The five "after" images correspond to durability tests A through E, respectively, that are described in the Materials and Methods section. These 30second tests did not remove the coatings entirely, as the "after" images show some small, low-relief remnants of material.
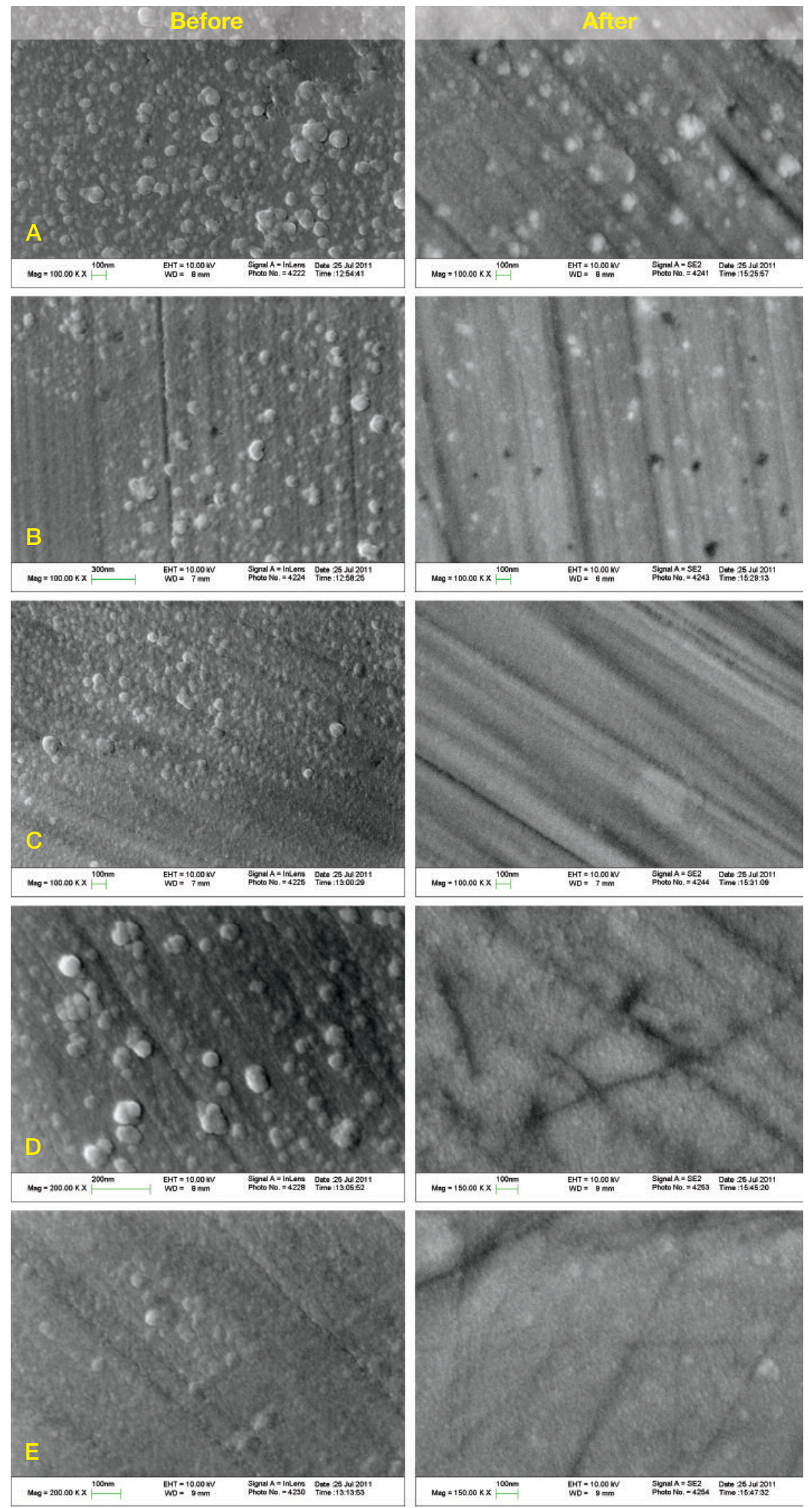


\section{SIMS: Sample CZ105}

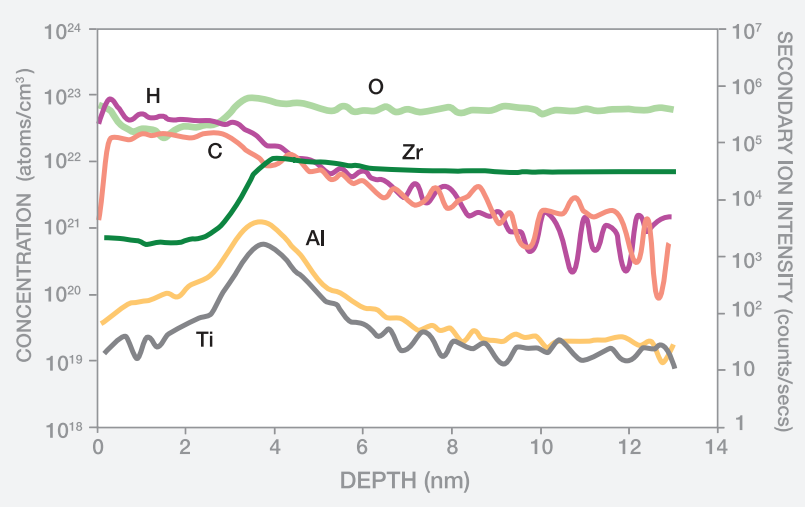

Figure 7. This SIMS depth profile of Diamantine sample CZ105 shows concentrations of $C$ and $H$ to depths of about $5 \mathrm{~nm}$, and concentrations of Ti and Al with highest values at about this same depth. These results suggest that the carbon-containing coating is about 5 $\mathrm{nm}$ thick. The presence of $\mathrm{Zr}$ and $\mathrm{O}$ directly on the sample surface when sputtering begins indicates that some areas of the CZ surface lack the coating layer.

\section{SIMS: Sample 3}

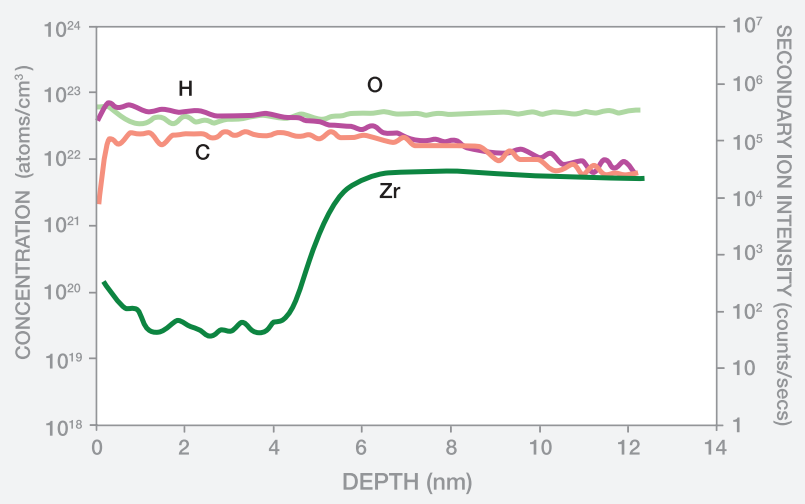

Figure 8. This SIMS depth profile is similar to the one shown in figure 7 , except the sample was not coated with the metallic adhesion layer or protective outer layer. As a result, the Ti and Al concentration profiles seen in figure 7 are absent here.

reported nanocrystalline synthetic diamond component of the Diamantine coating; such a finding would require SEM examination.

SIMS Characterization. Concentration depth profiles through the coating layer into the CZ substrate are presented for commercial Diamantine sample CZ105 (figure 7) and for CZ sample 3, a coated specimen that did not include the adhesion and protective layers (figure 8). As both figures show, $\mathrm{C}$ and $\mathrm{H}$ were detected at the surface, and their concentrations decreased by about a factor of 100 within approximately $5 \mathrm{~nm}$ of the surface. The $\mathrm{Al}$ and Ti concentrations of $\mathrm{CZ105}$ peaked at about the same depth, suggesting that the carbon-containing layer above the adhesion layer is only about $5 \mathrm{~nm}$ thick. It is unclear if the coating layer has a similar thickness on all facets of the CZ. The rate of sputtering by the beam was more consistent with amorphous carbon than with diamond, which indicates that amorphous carbon likely comprises a portion of the coating's content.

It should be noted that the coating thickness of approximately $5 \mathrm{~nm}$ documented by the SIMS analyses of these two samples does not match the $\sim 30-50 \mathrm{~nm}$ coating reported on the Serenity website (TEM image no. 4 indicates $30 \mathrm{~nm}$ ). Explanations for this discrepancy could include: (1) inconsistent application of the coating from one sample to another (or within a given sample); (2) inadvertent removal of the coating by standard cleaning and handling, as in the "after" images of figure 6 ; (3) the possibility that the coating had been removed entirely and the detected carbon was simply due to contamination; and (4) the possibility that the SIMS analysis under-represented the true thickness. The detection of $\mathrm{Zr}$ and $\mathrm{O}$ at the surface of the samples immediately upon sputtering suggests there may be areas where no coating was present, which agrees with the HRTEM images on Serenity's website that appear to show a nonuniform deposition of the coating.

As stated above, Serenity's website describes the coating as consisting of three layers-an adhesion layer, a layer containing the "nanocrystalline diamond" particles, and a protective outer layer. Based on our SIMS results, we could not chemically differentiate these three layers.

\section{DISCUSSION}

According to the determination made in the October 2009 EAG study, both coated samples tested by SIMS showed a carbon concentration of $2.5 \times 10^{22}$ atoms $/ \mathrm{cm}^{3}$ in the coating layer (again, see figures 7 and 8). This value is a fraction of the reported density for nanocrystalline diamond $\left(1.74 \times 10^{23}\right.$ atoms $/ \mathrm{cm}^{3}$ or $\left.3.5 \mathrm{~g} / \mathrm{cm}^{3}\right)$ and diamond-like carbon $\left(1.46 \times 10^{23}\right.$ atoms $/ \mathrm{cm}^{3}$ or 2.9 $\mathrm{g} / \mathrm{cm}^{3}$ ), which likely indicates that a lower-density matrix material forms the dominant portion of the coating on Diamantine.

From the reported thickness of $30 \mathrm{~nm}$ provided by Serenity, we determined the maximum amount of 
carbon that could be deposited in the coating. These values can be combined with the surface area of the CZ to calculate the volume of carbon added to the entire stone. For a representative round brilliant $\mathrm{CZ}$ with a weight of $1.76 \mathrm{ct}(6.49 \times 6.52 \times 3.88 \mathrm{~mm})$, we estimated a total coating surface area of $86.5 \mathrm{~mm}^{2}$. If the entire coating were composed of nanocrystalline synthetic diamond, which we know is not the case, the $30 \mathrm{~nm}$ carbon coating would add a weight of $\sim 9.0$ $\mu \mathrm{g}$ or approximately $0.000045 \mathrm{ct}$. The added weight of the actual nanocrystalline synthetic diamond particles would be less than this value because they appear to be a small component of a non-diamond matrix, and they would likely be removed by handling.

To put a coating thickness of $30 \mathrm{~nm}$ into perspective, consider that if this coating consisted of nanocrystalline synthetic diamond (assuming a lattice spacing of $0.357 \mathrm{~nm}$ ), it would only be 84 atoms thick. As our results show, this coating-regardless of the actual form of the carbon-does not add to the durability of the CZ, nor does it appear to be stable to normal wear and cleaning. Therefore, it is difficult to ascertain the gemological value added by these thinfilm colorless coatings.

The absence of any Raman peaks associated with diamond is not surprising, given the extreme thinness of these coatings and the likelihood that carbon is not the dominant component of the thin film. Also, it is likely that we were unable to detect the diamond Raman peak because the coating was no longer present on the CZ. The Raman spectrum provided for the coating on the Serenity website was collected using a different substrate material; $\mathrm{CZ}$ was not used in that instance due to its background signal (S. Neogi, pers. comm., 2009|. To our knowledge, then, the characteristic Raman peak for diamond has not been observed from any nanocrystalline synthetic diamond-coated CZ.

Previous studies of Serenity-coated colored diamonds (see Shen et al., 2007) with coatings as thick as $40 \mathrm{~nm}$ were unable to observe any coating-related peaks using PL spectroscopy. Most gemological laboratories are not equipped to measure or identify such thin coatings, and much of the equipment needed for such a surface analysis is time-consuming, prohibitively costly, or destructive. If such coatings become more prevalent within the gem trade and require identification, instrumentation and testing techniques may need to be added to the gemological laboratory repertoire.

Our SEM results strongly suggest that the Diamantine coating is not durable and does not reliably adhere to the underlying CZ. The SEM results appear to explain the thinness of the carbon layer measured by SIMS $(\sim 5 \mathrm{~nm})$, as this value is closer to the typical thickness of adventitious carbon (i.e., contamination of $~ 1 \mathrm{~nm}$ by hydrocarbon species covering most surfaces that are exposed to air) than the thickness of the nanocrystalline synthetic diamond layer reported by Serenity.

Other studies have described nanocrystalline and polycrystalline synthetic diamond as a coating on materials such as silicon carbide (i.e., synthetic moissanite). Fan et al. (1996) used an interlayer of titanium carbide to improve the adhesion between the synthetic diamond crystals and the silicon carbide, and the lattice mismatch between diamond $(0.357 \mathrm{~nm})$ and silicon carbide $(0.308 \mathrm{~nm})$ is much lower than between diamond and cubic zirconia $(0.517 \mathrm{~nm})$. Those researchers reported polycrystalline synthetic diamond film thicknesses of 500-1000 nm, nearly 10 times thicker than those reported by Serenity for their coatings. Due to the synthetic diamond films' greater thickness and strong adhesion, Fan et al. easily characterized them with Raman spectroscopy and SEM.

Although the exact details of the coating process performed by Serenity are unknown to us, it is likely that the $\mathrm{CZ}$ is heated to a high temperature /during CVD synthetic diamond growth, the substrate is typically heated to $800-900^{\circ} \mathrm{C}$ ). Alternatively, one U.S. patent application describes a procedure in which a stone is immersed in a nanodiamond slurry and then dried in inert gas; the nanodiamonds adhere to the surface through van der Waals forces (Neogi and Neogi, 2010). This does not appear to be the method employed by Serenity on Diamantine. Nevertheless, our SEM results indicate that the coating lacks long-term durability and may have even disintegrated in the course of our testing. The most enduring effect of the coating process might be the annealing of the cubic zirconia and the continued presence of the metals used in the "adhesion layer," although more tests would be necessary to confirm this.

The reported thickness of these films $(30-50 \mathrm{~nm})$ contributes very little carbon to the coated stone. The films' thinness probably stems from the fact that the coating material likely contains nanocrystalline synthetic diamond, and is not made up of singlecrystal synthetic diamond. A non-single-crystal coating that is too thick would limit transparency. Additionally, the RI of nanocrystalline diamond (no higher than 2.34) is lower than that of diamond (2.418), so the visual effect of having a higher-RI coating material is not as great as if it were single-crystal diamond. 


\section{FURTHER DEVELOPMENTS}

As this article was being prepared in the fall of 2011, Serenity representatives informed us that they had developed a newer version of Diamantine. They said they had stopped distributing the older version to their vendors in the spring of 2011, though we had no difficulty purchasing this product in July. This older material still exists in the trade and among consumers, and a version of Diamantine is currently being marketed by a major retail jewelry chain in India.

Serenity officials also told us they had developed a handheld testing instrument for commercial sale that would detect the presence of the Diamantine coating. In June 2011, the company posted an online video that showed the operation of this new instrument, which has tweezer-like probes that make contact with two points on the stone being tested. The instrument's screen displays the word "Diamantine" only when it detects the coating; when a diamond, uncoated CZ, or other type of material is tested, the screen simply reads "Serenity Technologies."

So far we have been unable to obtain further information on the new instrument or have the opportunity to examine it. We assume the instrument detects the presence of metal components in the coating (e.g., $\mathrm{Al}$ and $\mathrm{Ti}$, or possibly another metal in the "new" version of this product) by testing for electrical conductivity. Such metallic components appear to have better adhesion to the CZ surface (as demonstrated by our EDXRF detection of Ti after the "diamond" coating may have been removed by our routine handling of Diamantine samples over a period of months). Since a diamond tests negatively on this device, the instrument apparently does not indicate whether the coating contains "nanoparticles of synthetic diamond."

\section{CONCLUSION}

Cubic zirconia that is coated with a thin surface layer of "nanocrystalline diamond" to allegedly improve its appearance and/or durability has been marketed by Serenity Technologies as Diamantine (figure 9). We could not observe the thin colorless coating on Diamantine with the optical microscope, or with most standard analytical techniques used by major gemological laboratories. SEM imaging detected a nanocrystalline coating on newly purchased Diamantine samples, but the coating on these gems was subsequently largely removed by rudimentary cleaning and handling. Therefore, the SEM images called into question the long-term durability of this coating. The only

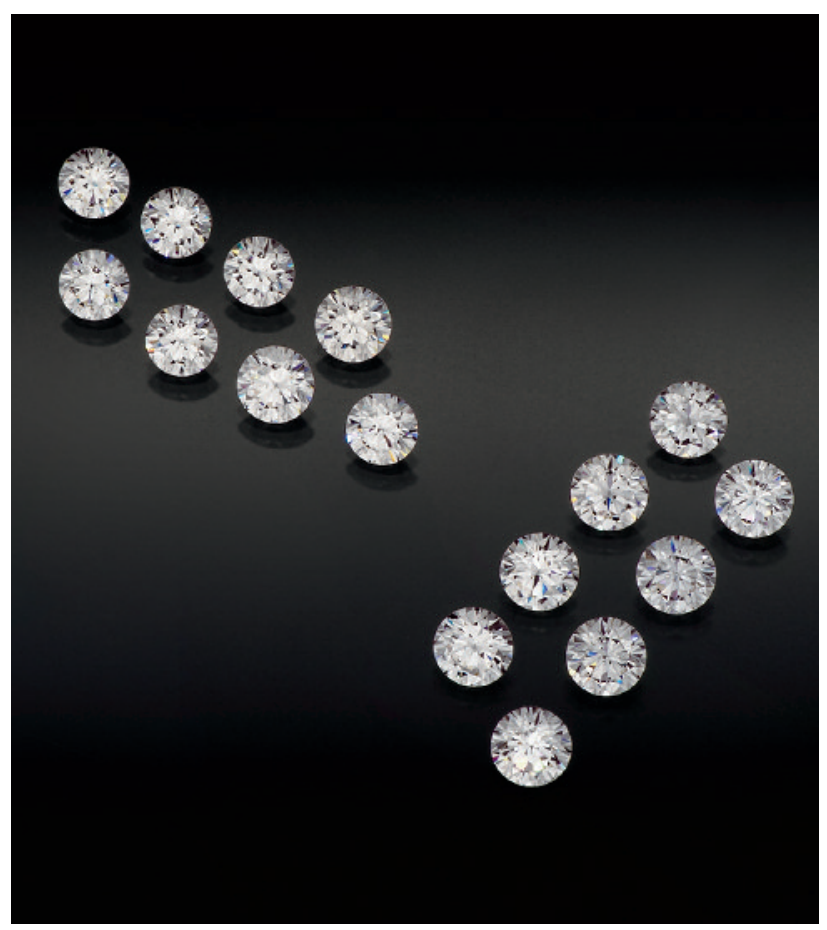

Figure 9. Several samples of uncoated CZ (left, 1.48$1.84 \mathrm{ct}$ ) are shown here, together with Diamantine (right, 1.70-2.07 ct). Photo by Robert Weldon.

technique that could establish whether the coating had ever existed was EDXRF, which detected the Ti from the metallic adhesion layer. Of course, this criterion is not useful for testing for coatings on Ti-bearing substrates.

We detected $\mathrm{C}, \mathrm{Ti}$, and $\mathrm{Al}$ using the SIMS technique, but we could not confirm that the carbon was in the form of diamond. The inability of Raman spectroscopy to detect the characteristic diamond peak at $1332 \mathrm{~cm}^{-1}$, assuming the actual presence of diamond, is likely due to the thinness and instability of the coating. The SIMS data indicated that the carbon-containing coating was only about $5 \mathrm{~nm}$ thick on the two samples that were analyzed.

Coatings of "synthetic diamond" deposited on diamond simulants should not be confused with synthetic diamonds in which the entire weight and volume of the gemstone is actually diamond. Advanced gemological testing is sometimes needed to distinguish synthetic diamond from natural diamond. However, like uncoated CZ, Diamantine is easily separated from diamond (natural or synthetic) on the basis of thermal conductivity, weight-to-diameter ratio, and specific gravity. 
Techniques for use in gemological laboratories for detecting coatings on gems will need to be refined in the future. Useful methods could include scanning electron microscopy (SEM) for high-magnification imaging and
Nomarski differential interference contrast microscopy for investigating the flatness of a surface. When a difference in refractive index is suspected between the coating and substrate, the ellipsometry technique may be useful.

\section{ABOUT THE AUTHORS}

Dr. Shigley (jshigley@gia.edu) is a distinguished research fellow, Mr. Gillbertson is a research associate, and Dr. Eaton-Magaña is a research scientist, at GIA in Carlsbad.

\section{ACKNOWLEDGMENTS}

The authors thank Jayant Neogi and Dr. Suneeta Neogi of Serenity Technologies for supplying samples of their Diamantine product, and for coating several CZ samples provided by GIA. Jerry Golech, an instructor in the Jewelry Manufacturing Arts program at GIA in Carlsbad, assisted with the durability tests. Dr. Troy Blodgett of GIA helped analyze the visual observation test results. Tim Thomas of GIA organized the study of the coated CZ samples at commercial analytical facilities. Dr. Chi Ma collected the SEM images and EDS spectra at Caltech. Karen Chadwick (formerly at GIA in Carlsbad) assisted with the gemological characterization.

\section{REFERENCES}

Bennet K.E., Kearnes R.H. (2009) Azotic ${ }^{\circledR}$ thin-film surface enhancement of gemstones. Canadian Gemmologist, Vol. 30, No. 1, pp. 20-34.

Eaton-Magaña S., Chadwick K.M. (2009) Lab Notes: Cubic zirconia reportedly coated with nanocrystalline synthetic diamond. $G \uplus G$, Vol. 45, No. 1, pp. 53-54.

Fan W.D., Jagannadham K., Goral B.C. (1996) Multilayer diamond coatings on silicon carbide. Surface and Coatings Technology, Vol. 81, No. 2/3, pp. 172-182, http://dx.doi.org/10.1016/02578972(95)02476-X.

Gielisse P.J. (1998a) Mechanical properties of diamond, diamond films, diamond-like carbon, and like-diamond materials. In M.A. Prelas, G. Popovici, and L.K. Bigelow, Eds., Handbook of Industrial Diamonds and Diamond Films, Marcel Dekker, New York, pp. 49-88.

(1998b) Mechanical properties of diamond films. In P.J. Gielisse, V.I. Ivanov-Omskii, G. Popovici, and M. Prelas, Eds., Diamond and Diamond-Like Film Applications, Technomic Publishing Co., Lancaster, PA, pp. 281-296.

Gruen D.M. (1999) Nanocrystalline diamond films. Annual Review of Materials Science, Vol. 29, pp. 211-259, http://dx.doi.org/ 10.1146/annurev.matsci.29.1.211.

Henn U. (2003) Gemmologische Kurzinformationen: Edelsteine met aufgedampften, hauchdünnen Metallschichten [Gemmological short notes: Gemstones sputtered with metallic thin films]. Gemmologie-Zeitschrift der Deutschen Gemmologischen Gesellschaft, Vol. 52, No. 1, pp. 41-44.

Herrera-Gomez A., Sun Y., Aguirre-Tostado F.-S., Hwang C., ManiGonzalez P.-G., Flint E., Espinosa-Magaña F., Wallace R.M. (2010) Structure of ultra-thin diamond-like carbon films grown with filtered cathodic arc on Si(001). Analytical Sciences, Vol. 26, No. 2 , pp. 267-272, http://dx.doi.org/10.2116/analsci.26.267.

Huang B.R., Chen K.H., Ke W.Z. (2000) Surface-enhanced Raman analysis of diamond films using different metals. Materials Letters, Vol. 42, No. 3, pp. 162-165, http://dx.doi.org/10.1016/ S0167-577X(99)00176-7.

Koivula J.I., Kammerling R.C., Eds. (1991) Gem News: Faceted gems coated with diamond-like carbon. $G \uplus G$, Vol. 27, No. 3, p. 186. Mednikarov B., Spasov G., Babeva T., Pirov J., Sahatchieva M., Popov
C., Kulisch W. (2005) Optical properties of diamond-like carbon and nanocrystalline diamond films. Journal of Optoelectronics and Advanced Materials, Vol. 7, No. 3, pp. 1407-1413.

Moses T.M., Johnson M.L., Green B., Blodgett T., Cino K., Geurts R.H., Gilbertson A.M., Hemphill T.S., King J.M., Kornylak L., Reinitz I.M., Shigley J.E. (2004) A foundation for grading the overall cut quality of round brilliant cut diamonds. $G \uplus G$, Vol. 40, No. 3, pp. 202-228, http://dx.doi.org/10.5741/GEMS.40.3.202.

Neogi S., Neogi J. (2010) Method for Producing Nanocrystalline Diamond Coatings on Gemstones and Other Substrates. U.S. Patent Application 20100068503 A1, March 18.

Ogden J. (2008) A coat of many colours. Gems e) Jewellery, Vol. 17 No. 1, pp. 9-11.

Patterson J.R., Catledge S.A., Vohra Y.K., Akella J., Weir S.T. (2000) Electrical and mechanical properties of $C_{70}$ fullerene and graphite under high pressures studied using designer diamond anvils. Physical Review Letters, Vol. 85, No. 25, pp. 5364-5367, http://dx.doi.org/10.1103/PhysRevLett.85.5364.

Potocky S., Kromka A., Potmesil J., Remes Z., Polackova Z., Vanecek M. (2009) Growth of nanocrystalline diamond films deposited by microwave plasma CVD system at low substrate temperatures. Physica Status Solidi (a), Vol. 203, No. 12, pp. 3011-3015.

Prawer S., Nemanich R.J. (2004) Raman spectroscopy of diamond and doped diamond. Philosophical Transactions of the Royal Society A, Vol. 362, No. 1824, pp. 2537-2565, http://dx.doi.org/ 10.1098/rsta.2004.1451.

Schmetzer K. (2008) Surface treatment of gemstones, especially topaz - An update of recent patent literature. Journal of Gemmology, Vol. 31, No. 1/2, pp. 7-13.

Shen A.H., Wang W., Hall M.S., Novak S., McClure S.F., Shigley J.E., Moses T.M. (2007) Serenity coated colored diamonds: Detection and durability. GÆG, Vol. 43, No. 1, pp. 16-33, http://dx.doi.org/10.5741/GEMS.43.1.16.

Willis C. (1970) The complex refractive index of particles in a flame. Journal of Physics D: Applied Physics, Vol. 3, No. 12, pp. 1944 1948, http://dx.doi.org/10.1088/0022-3727/3/12/324.

Zaitsev A.M. (2001) Optical Properties of Diamond: A Data Handbook. Springer Verlag, Berlin, 502 pp. 